\title{
REFLEJOS EN ESFERAS NAVIDEÑAS
}

\author{
Carlos Atzin*
}

Mi infancia no está en todos los lugares, aunque por estas fechas, las esferas sí.

De la covacha a la ventana principal, solo una vez al año nos importan, solo una vez al año son frutos.

Todo los otros meses cerca de arañas, consolas en desuso y fotos viejas.

Fotos donde fantasmas

niegan a la muerte con su cuerpo.

Mi mamá las conserva

desde la meningitis de mi hermano mayor.

No conocen veranos o el drenaje.

La arena y el silicio, botellas sin alcohol y hasta piedras en hornos recibieron paralelos y meridianos. Manos anteriores le dieron coordenadas al vidrio que en el fuego se hizo elástico y soplos de otras bocas volvieron terredad algo molido.

Creo en el cielo que esconde cada una $y$ en lo que han reflejado:

el entierro de un poodle en el jardín y un cachorro de schnauzer blanco y negro que busca un hueso encima de su tumba;

* Carlos Atzin (1991, Toluca) estudió la licenciatura en Comunicación Social en la Universidad de la Comunicación. Fue becario en el área de poesía en la Fundación para las Letras Mexicanas. 
el incendio del monte en Noche Buena y la caída de mi abuela que no acaba. Su condición de espejos ya cerrados sugieren paisajes que no existen: una lluvia de arroz siempre lejana o la pesadilla crónica donde mi papá se suicida conmigo metiendo el auto en el mar.

Veo mi retrato: canas a los 27 , por los sueños en blanco de mi madre. Un cuerpo tan delgado siempre ama más de lo que promete, o al menos eso cree.

El abrazo de los desconocidos en sueños pesa más que el de gente que me amó. En este sillón recostaba a mi abuelo, la última vez que lo vi preguntó por mi nombre cada cinco minutos.

Los centauros con arco dirigen mi destino desde estrellas remotas, reinos de unos reyes terrestres que ya nunca volvieron a ningún horizonte de estas esferas que mi madre guarda. 